\title{
The Research of Teaching Reform of MSP430 Single Chip Computer Course
}

\author{
Weimin Qi \\ School of Physics and Information Engineering \\ Jianghan University \\ Wuhan, China \\ qwmin@163.com \\ Xia Zhang \\ School of Physics and Information Engineering \\ Jianghan University \\ Wuhan, China \\ zx1964@163.com
}

\author{
Qun Hou \\ School of Physics and Information Engineering \\ Jianghan University \\ Wuhan, China \\ viphouqun@163.com \\ Zhiming Wang \\ School of Physics and Information Engineering \\ Jianghan University \\ Wuhan, China \\ leolink@163.com
}

\begin{abstract}
In view of the characteristics of MSP430 singlechip curriculum design, we focused on the organization of teaching content, improved teaching methods and reformed the performance assessment methods to mobilize students' interest and enthusiasm, so that they can through the curriculum design of this important practical teaching links, apply the knowledge and theory to practice. The teaching reform had achieved a good teaching effect, at the same time, the proposed teaching methods and measures also have certain reference significance for the teaching reform of other practical courses.
\end{abstract}

Keywords-MSP430; teaching reform; curriculum design

\section{INTRODUCTION}

With the progress of era and the development of electronic technology, as well as the application of Internet of things industry at present, single-chip microcomputer technology as one of the key technology of Internet of things industry got a broader opportunities for development and application prospect. In order to adapt to the market demand, the teaching content of single-chip computer courses in colleges and universities is gradually transitioned from MCS-51 to the relatively complex but less power-consuming MSP430 series. Because MSP430 courses need more knowledge, the students have difficulty to practice to master; this paper discusses the teaching reform of MSP430 curriculum design, to encourage students to apply the knowledge to practice in a short time. At the same time, the various knowledge points are organically combined to improve students' practical ability, while improving the teaching methods such as experimental mode and achievement evaluation.

\section{THE MAIN CONTENT OF THE REFORM}

MSP430 is an ultra-low power and high-performance 16bit hybrid signal processor produced by TI. It can be used to integrate many analog circuits, digital circuits and microprocessors on a single chip to provide "monolithic" solutions. Although the MSP 430 series of single-chip microcomputer is not very long, but due to its unique and excellent performance, the development is extremely rapid, the application is becoming more and more extensive, which can be applied to many traditional single-chip applications, such as instrumentation, automatic control and consumer products, which are also suitable for some low-power portable products with battery power supply $[1,2]$.

Given the universality and practical applicability of the MSP430 application, many universities have opened MSP430 single-chip microcomputer courses to broaden the scope of employment and enhance the employment skills of students. It has become an important course in electronic majors in engineering universities [3].

This course involves a wide range of knowledge, almost covers the knowledge needed for the electronic system design content, and practicality is strong, not only through the theory of classroom teaching to improve students' practical ability and practical ability. Although some experimental courses have been arranged in the course of classroom teaching, the practice ability of students has been improved, but it still has a certain gap with the practical ability expected by the electronic system design enterprises. How to further improve the students' ability to design the electronic system based on MSP 430 microprocessors is an urgent problem that the teaching staff must think seriously and put into practice.

\section{A. Reform of Teaching Content and Teaching Methods}

Compared with MCS-51 single-chip microcomputer, MSP 430 SCM not only has a certain degree of difficulty and depth in theory, but also has greater operational space in the design flexibility and innovation [4].

The course design link plays an important role in the practice teaching, On the one hand, it will integrate the basic knowledge into a comprehensive application, and on the other hand, it will lay a good foundation for future graduation design and electronic competition. Therefore, the course design of MSP430 should not only reflect the grasp of the key knowledge of single-chip microcomputer, but also integrate the 
design topic to further study the knowledge point. Therefore, this teaching reform has made some adjustments to the teaching content and methods

- Integration of Theory and Practice Teaching. In the early stage, the common modules in the design process are further strengthened, and the theoretical difficulties and doubts are solved quickly. Through the in-depth and detailed explanation of the logic relation of module circuit diagram, the function of the key module of MSP 430 single chip microcomputer is strengthened. When teaching MSP 430 each module, we send a module logic function circuit diagram to the student, so the main content of MSP $430 \mathrm{MCU}$ can be quickly mastered in a very short time. At the same time, we emphasizes some practical examples of the module in actual design. For example, when teaching the most commonly used and most important timer capture function, In addition to the logic structure and usage rules of timer $A$, the eight working modes of the output port are also analyzed, and the design examples commonly used in each work mode are also analyzed. The combination of the key teaching and assessment of each teaching method in the process of the educational reform has obtained the good teaching effect, enables students to get into advanced application design more easily on this basis [5,6].

- MSP430 curriculum design consists of familiar with the IAR EW development environment and mastering the MSP430 microprocessor chip function module structure, principle and application of two parts content. When introducing IAR EW development environment, students are required to operate IAR EW development environment in the lab at the same time, so as to create the conditions for the study of this course, so that students can learn the new project of the development environment, source document editing, source files to add to the new project, the configuration, compilation, connection and debugging of the new project and development environment. The knowledge of functional modules in MSP430 is mastered in the development and design of MSP 430 electronic system and familiar with the development environment of IAR EW. In practice, the sub-module has mastered its principle, structure and programming Settings of each register. After learning the MSP 430 system structure and system clock module, the students began to design, make and weld the MSP430 minimum system, and students will have a better understanding of the MSP 430 microprocessor during the production process. On this basis, to the input/output port of the module teaching and practice, introduced the working principle, structure, and the input/output port register after the meaning and application method, the student to make the circuit of input/output port programming, validation and application of the oscilloscope observation, thus deepening and master the function of the module and application $[7,8]$.

- The Choice of Practical Development Platform. At present, most colleges and universities use a variety of fully functional experimental boxes or development boards, and its obvious drawback is that because the links of each interface on the experimental box are fixed, most students will not actively understand the working principle of this connection circuit, and they have not experienced the whole process of design, component connection, debugging, etc. Moreover, the experimental box has limited resources, and some students with strong practical ability cannot carry out the design and innovation of complex hardware schemes. For the above reasons, this course adopts the minimum system of MSP 430 single-chip microcomputer core board with key input module and digital tube display module. This choice is because MSP 430 single-chip microcomputer is very common in the use of the pin multiplexing function, and all the external pins of MSP 430 single chip are free for students to choose.

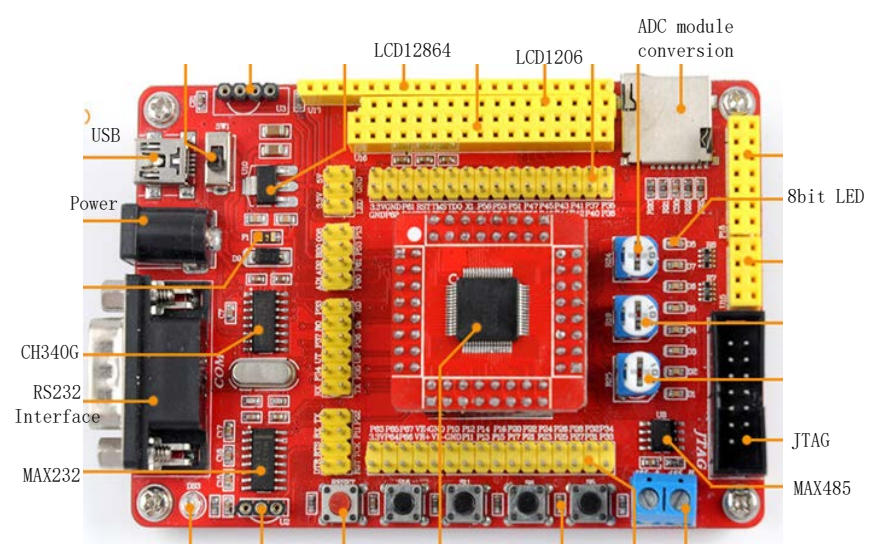

Fig.1. MSP430 development board

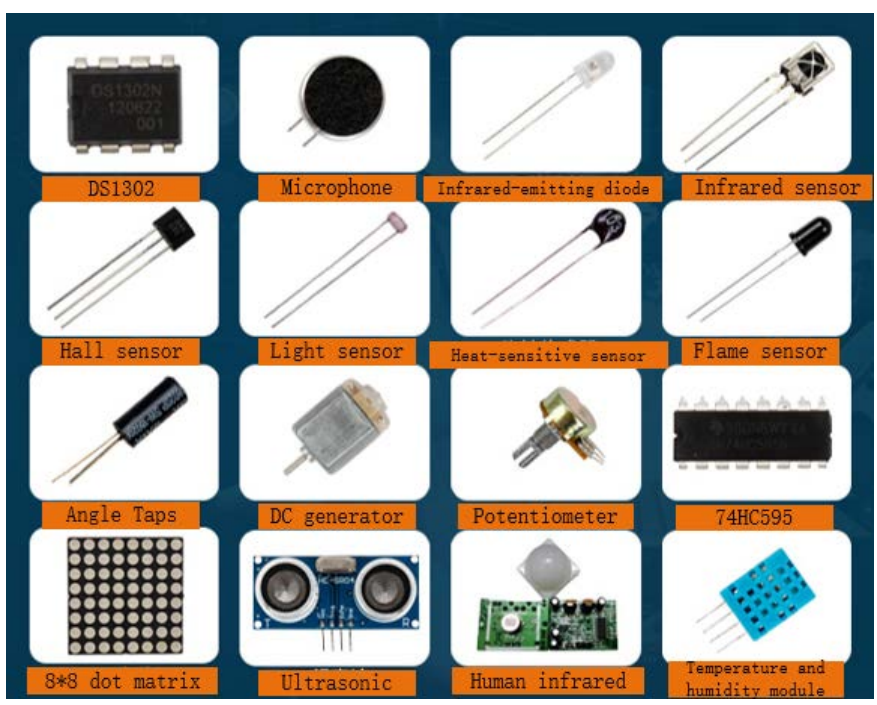

Fig.2. Various sensors used in the experiment

On the one hand, it can enhance students' understanding of ports, and also enable students to experience the powerful functions of MSP430 singlechip. In addition, it also provides a convenient choice for the external temperature module, infrared module and gravity sensor module. On the other hand, students have greater freedom and choice space in curriculum design, creating a loose 
hardware experiment environment and creative space. Through the development platform, students are familiar with the function of MSP430 pins, and designed the experimental scheme to promote their understanding of theoretical teaching and improve students' practical ability. The platform is shown in Fig.1; Various sensors used in the experiment are shown in Fig.2.

- A Project-led Experimental Model. The course design is different from the general verification experiment course, which is based on theoretical teaching and takes practice and innovation as the main line to improve the teaching link of students' comprehensive ability. At the past, because the hardware structure of the MCS - 51 single chip microcomputer course design is relatively simple, function of peripheral interface is simple. There is limited space for students to design freely. Therefore, the teaching mode adopts the traditional "infusion" teaching method, and most of the design tasks for students are relatively single topic. The educational reform have made further exploration on the teaching mode and adopted the experimental teaching mode based on project-led. The teaching model aims to improve students' comprehensive quality and students as the center, and design the teaching content of the whole course into a project library that covers all key teaching contents. Among them, there are different design projects for each important knowledge point, and students can select and complete multiple design topics according to their own abilities and interests. The problems in the design of the project library are different and varied, reflecting the concept of education, which is taught in accordance with their aptitude, and a summary of previous experience in the course design teaching $[9,10]$.

- In the teaching process of the above modules, the teacher actively introduces students to the mainstream technology and the latest development in the field of SCM, such as the C8051 F series and ARM series processor of the system, and combines the teacher's research to create conditions for the students to demonstrate the practical engineering application of the single chip computer, and stimulate the students' interest in learning. Students are encouraged to participate in the electronic design competition in the school, and to find outstanding students in the competition in the school, and to participate in the electronic design competition in cities, provinces and countries. About 50 percent of the students in the e-information majors participate in the competition, and 20 percent of students participate in the high level competition. Among them, the outstanding students will also form a scientific research group, apply for the science and technology innovation project of university students in the province and city, and complete a scientific research project under the guidance of teachers $[9,10]$.

\section{B. Perfect Experimental Teaching Condition}

The effect of teaching reform is mainly through the evaluation of student achievement. Student achievement evaluation is a

- IAR EW430 experimental platform is adopted. The "MSP 430 electronic system design" course, commonly used and well - performing development environment is IAR EW430 platform developed by IAR company. This platform has the efficient compilation performance, can support a variety of development tools, support output TI - TXT the target file, reference resource is rich, it is the first choice of MSP430 single chip microcomputer application development at present.

- Install full function emulator MSP430. The MSP 430 full-function emulator supports JTAG/SBW simulation debugging of the full series MSP430FLASH single chip microcomputer, and BSL volume production. The current application of the most widely used USB interface, compatible with the interface debugging tools. The non-parallel computer can also conveniently use the USB interface to develop and debug the MSP 430 series singlechip. The simulator can be used widely in teaching and research and development.

- Optimize the Experimental Hardware Environment. In the traditional teaching and experiment, student experiment is often completed in the ready-made experiment box, the experiment content only require students to plug a few lines in the experiment box, can complete the experiment verification, electronic system design and development to the student ability raise wouldn't help very much. Therefore, students should be improved to the design of the real MSP 430 electronic system from the experimental method of this experimental box. Therefore, it is necessary to perfect and optimize the experimental hardware environment, including basic circuit welding platform, circuit testing, debugging equipment and other hardware environment.

\section{Effect of Educational Reform}

The effect of teaching reform is mainly through the evaluation of student achievement. Student achievement evaluation is an important link in the teaching process of teachers, which has important guiding effect on teachers' teaching and students' learning. The traditional teaching evaluation model obviously does not reflect the whole work of the students in the course design process. Therefore, it is necessary to establish a diversified evaluation system, which should pay attention to the innovation reflected by the students in the design process, and also take into consideration the difference between each student's basic and ability, and improve the students' score in the design process. This diversified assessment method can fully mobilize students' subjective initiative and improve students' consciousness of innovation and competition. At the same time, the learning situation and learning effect of students in curriculum design are reflected from different perspectives.

- Improved student electronic system design and development and practical ability. Through improved 
teaching method, students can basically complete the practical skills of electronic system design, development, plate making, welding and debugging, and meet the requirements of the society for students' practical ability.

- Promote the improvement of teachers' scientific research ability. Teachers achieve the teaching method reform at the same time, the need to constantly from production practice of comprehensive, applied electronic system development project, not only provide students with the content of the development of classroom teaching, but also improves the teachers' scientific research ability, has the practical significance

- To promote the construction of teaching laboratories. To meet the needs of the MSP430 electronic practice teaching system, improving experiment teaching environment and condition, and constantly improve the electronic system design of hardware and software environment, in the original based on MSP430 electronic experiment box increased hardware welding and debugging test equipment, meet the requirement of comprehensive electronic experiment system development, and promote the construction of the laboratory.

\section{CONCLUSION}

MSP430 single-chip microcomputer course design is an important practical course for electronic majors, especially in the cultivation of innovative talents has great practical significance. Through this teaching reform, the reform ideas and concrete implementation methods are put forward in the teaching process, development platform selection, experimental mode and achievement evaluation method, and then implemented in the following teaching process. These reform measures have obtained good teaching effect in actual teaching process.

\section{ACKNOWLEDGMENT}

This work is supported by Key Project of Wuhan Education Bureau (Project Numbers: 2014004)

\section{REFERENCES}

[1] Z.Q. Li. "MSP430 series ultra-low power single chip microcontroller principle and system design,” $\mathrm{Xi}$ 'an: $\mathrm{Xi}$ 'an electronic science and technology university press, 2008.

[2] J.H.Shen and Y.Q. Yang, "Principle and application of MSP430 ultralow power microcontroller,” Beijing: tsinghua university press, 2013.

[3] Nagy C . Embedded Systems Design Using the TI M SP430 Series[M] . London: Newnes, 2003.

[4] Z. Z. Wang, “An example of MSP430 single-chip microcomputer based on computer simulation technology," Laboratory research and exploration, vol.9, pp. 94-97, 2013.

[5] W. J. Huang and J. Q. Xiao, "Research on the teaching reform of 'single chip microcomputer principle and application',” Journal of electrical and electronic teaching, vol. 6, pp. 29-30, 2010.

[6] Y. Song, C. Y. Yu and Z.J. Zhang, "The practical teaching reform of the single-chip high-quality courses," Laboratory research and exploration, vol. 3, pp. 83-85, 2009.

[7] L. Chen, "Teaching reform of single-chip computer courses," Laboratory research and exploration, vol. 9, pp. 121-123, 2008.

[8] X. H. Zhou, J. J. Li, "Discussion and research on practical teaching of single-chip microcomputer,” Experimental technology and management, vol. 7, pp. 120-122, 2007.

[9] X.M. Lin, "Design of low-power gas meter system based on MSP430," Measurement and control technology, vol. 2, pp. 8-15, 2014.

[10] F. Guan, X. Huang and H.Z. Hu, "Design of portable heart rate monitor,” Instrument technique, vol. 1, pp. 37-39, 2014. 